\title{
Transcatheter arterial chemoembolization-induced bile duct necrosis with hemobilia in hepatocellular carcinoma: endoscopic visualization and repair
}

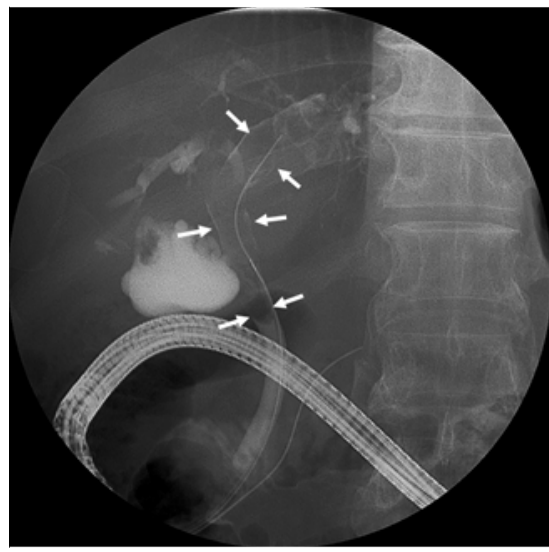

- Fig. 1 Radiographic image during endoscopic retrograde cholangiopancreatography showing multiple filling defects in the bile duct (arrows).

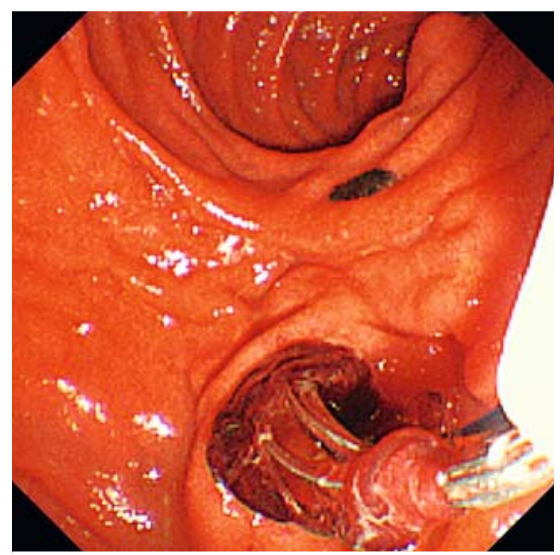

- Fig. 2 Endoscopic view during endoscopic retrograde cholangiopancreatography showing the extraction of blood clots from the bile duct using a basket.

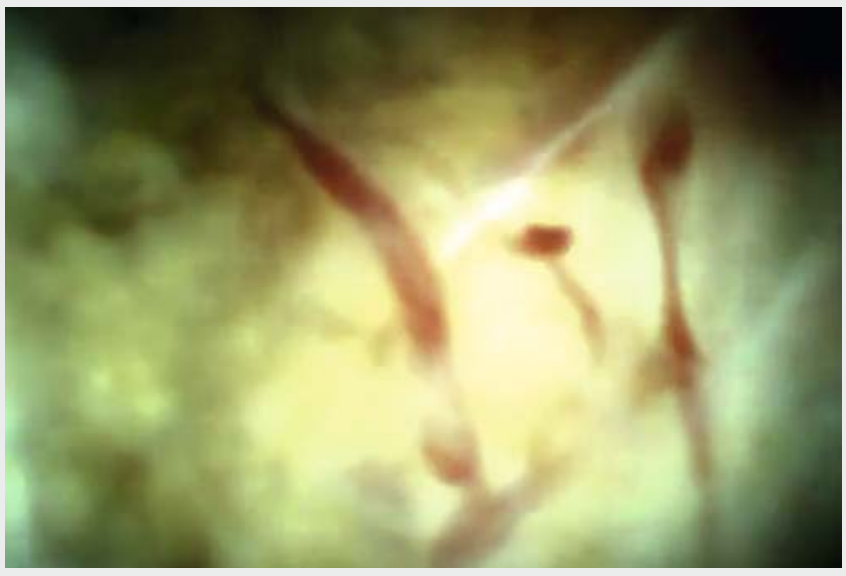

$\checkmark$ Video 1 Single-operator cholangioscopy using the SpyGlass DS System showing blood clots, invasion of hepatocellular carcinoma, and pulsating vessels with evidence of bleeding on the damaged bile duct.

Transcatheter arterial chemoembolization (TACE) has been widely used as a palliative treatment for patients with unresectable hepatocellular carcinomas (HCCs) [1]. TACE is a relatively safe procedure, with a complication rate of $<1 \%$ [2]. Hemobilia after TACE has very occasionally been reported [3], but endo- scopic visualization of hemobilia has not been reported.

A 63-year-old man presented to our hospital with abdominal pain, fever, and jaundice. He had been diagnosed 3 months earlier with alcoholic liver cirrhosis and unresectable HCC ( $4 \mathrm{~cm}$, segment 8 ), and had been treated with TACE in our

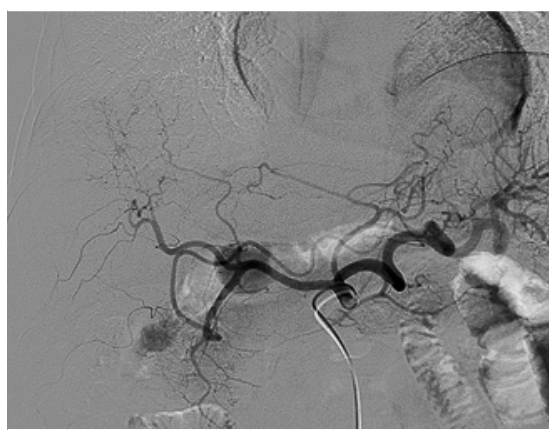

- Fig. 3 Angiography image showing no extravasation of contrast to the bile duct.

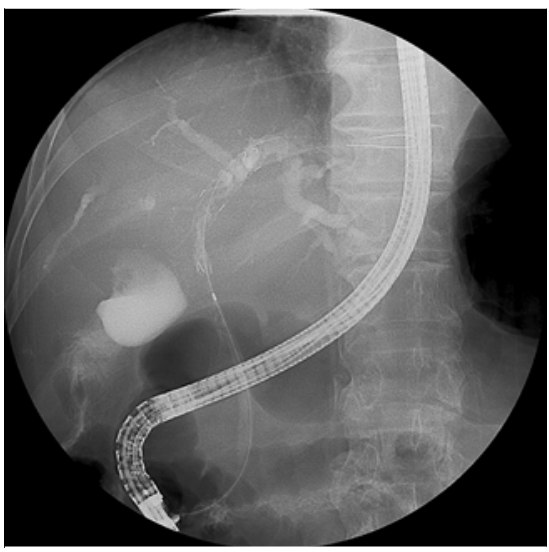

- Fig.4 Radiographic image showing placement of a self-expandable metal stent in the bile duct to compress the bleeding focus and provide biliary drainage.

hospital. His laboratory test results were as follows: total bilirubin $10.5 \mathrm{mg} / \mathrm{dL}$; aspartate transaminase $1098 \mathrm{IU} / \mathrm{L}$; and alanine transaminase $891 \mathrm{IU} / \mathrm{L}$. Computed tomography (CT) revealed newly developed intraductal masses or blood clots in the common bile duct (CBD) and intrahepatic duct (IHD), with upstream IHD dilatation. Endoscopic retrograde cholangiopancreatography (ERCP) revealed multiple filling defects in the bile duct ( Fig.1). Multiple blood clots were extracted with a stone basket and balloon catheter ( $\mathbf{F i g . 2}$ ). Therefore, hemobilia 
was suspected. After the ERCP, the abdominal pain and fever improved.

On day 3 after the ERCP, the patient experienced dizziness, melena, and a progressive decrease in hemoglobin level. Angiography revealed no extra flow of contrast to the bile duct ( $\triangleright$ Fig.3). Repeat ERCP with single-operator cholangioscopy (SpyGlass DS; Boston Scientific, USA) was performed to identify the bleeding focus ( $\vee$ Video 1 ). Cholangioscopy revealed many blood clots in the CBD. A tumorous mass in the hepatic hilum suggested direct HCC invasion of the bile duct. Cholangioscopy also revealed active bleeding from the left IHD, at the distal end of the tumor. After further advancement of the cholangioscope, we observed a damaged bile duct owing to ischemic damage after TACE. Small pulsating blood vessels on the surface of the bile duct showed active bleeding. A self-expandable metal stent was placed to compress the bleeding bile duct ( Fig.4). Thereafter, the patient's condition stabilized without further evidence of bleeding.

To the best of our knowledge, this is the first reported case of post-TACE hemobilia diagnosed using cholangioscopy. Identifying the bleeding focus accurately using cholangioscopy can help to determine the most appropriate treatment method.

Endoscopy_UCTN_Code_CPL_1AK_2AI

\section{Competing interests}

The author declares that he has no conflict of interest.

The author

\section{Chi Hyuk Oh}

Division of Gastroenterology and Hepatology, Department of Internal Medicine, Kyung Hee University Hospital, Seoul, Republic of Korea

\section{Corresponding author}

\section{Chi Hyuk Oh, MD, PhD}

Division of Gastroenterology and Hepatology, Department of Internal Medicine, Kyung Hee University Hospital, 23 Kyungheedae-ro, Dongdaemun-gu, Seoul 02447, Republic of Korea harrison@daum.net ochihyuk@gmail.com

\section{References}

[1] Ngan H, Lai CL, Fan ST et al. Treatment of inoperable hepatocellular carcinoma by transcatheter arterial chemoembolization using an emulsion of cisplatin in iodized oil and gelfoam. Clin Radiol 1993; 47: 315-320

[2] Tu J, Jia Z, Ying $X$ et al. The incidence and outcome of major complication following conventional TAE/TACE for hepatocellular carcinoma. Medicine (Baltimore) 2016; 95 : e5606
[3] Nishi M, Saeki I, Yamasaki T et al. Hemobilia immediately after transcatheter arterial chemoembolization using drug-eluting beads for hepatocellular carcinoma with intrahepatic bile duct invasion. Hepatol Res 2018; 48: 329-332

\section{Bibliography}

Endoscopy 2021; 53: E265-E266

DOI $10.1055 / \mathrm{a}-1260-2874$

ISSN 0013-726X

published online 1.10 .2020

(c) 2020. Thieme. All rights reserved.

Georg Thieme Verlag KG, Rüdigerstraße 14, 70469 Stuttgart, Germany

\section{ENDOSCOPY E-VIDEOS}

https://eref.thieme.de/e-videos

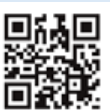

Endoscopy E-Videos is a free access online section, reporting on interesting cases and new

techniques in gastroenterological endoscopy. All papers include a high quality video and all contributions are freely accessible online.

This section has its own submission website at https://mc.manuscriptcentral.com/e-videos 